\title{
Analysis of Physicochemical Parameters, Anions and Main Heavy Metals in Rainwater of Bangladesh Rajshahi City Company
}

\author{
Md. Mahtab Ali Mollah', Md. Rafiqul Islam², Nurunnaher Mollica ${ }^{3}$, Md. Rakib-uz-Zaman ${ }^{4}$, \\ Sayed M A Salam ${ }^{5}$ \\ ${ }^{1}$ Environmental Pollution Studies Laboratory, Department of Applied Chemistry and Chemical Engineering, Faculty of Engineering, \\ University of Rajshahi, Rajshahi-6205, Bangladesh \\ ${ }^{1}$ Correspondence Author Email: md.mahtabali@yahoo.com
}

\begin{abstract}
This study was carried out to determine the physicochemical properties and heavy metal concentration of rain water from twenty different sites in Rajshahi City Corporation area of Bangladesh. Rain water samples were collected during the rainy season and analyzed for various parameters such as temperature, odor, color, transparency, electrical conductivity, turbidity, total dissolved solid, pH, total hardness, chloride, nitrate, sulphate, lead, cadmium, manganese, chromium and arsenic. The ranges of parameters such as temperature, electrical conductivity, turbidity, total dissolved solid, $\mathrm{pH}$, total hardness, chloride, nitrate and sulphate were: $28.8-29.1^{\circ} \mathrm{C}$, 8-20.33 $\mathrm{\mu Scm}^{-1}, 2.33-4.88 \mathrm{NTU}$, 5.6-14.29 ppm, 6.03-6.99, 4.8-15.2 ppm, 0-7.81 ppm, 0-5.9 ppm and 0-13 ppm, respectively. The rainwater samples were odorless, colorless and transparent. The $\mathrm{pH}$ values of the samples show that rain water over the Rajshahi City Corporation area is slightly acidic. All the parameters studied have been discussed in detail using international standards applicable to potable water. The ranges of heavy metal concentrations such as lead, cadmium, manganese, chromium and arsenic were: 1.0024 11.9124 ppb, 0.0501-0.494 ppb, 0.2035-1.75 ppb, 0.05002-1.974 ppb and 1.531-2.7465 ppb. The heavy metal concentrations of rainwater samples are within the permissible limit for drinking purpose in almost all places during the investigation period. Rain water quality of this investigation area, is found suitable for most uses including drinking.
\end{abstract}

Keyword: Rajshahi City Corporation, Heavy metals, Total dissolve solid, Electrical conductivity, Total hardness, Rainwater

\section{Introduction}

Rain is an important source of fresh water especially for those who live in natural areas, where water use is limited due to scarcity or where surface and underground water quality is poor. Rainwater has long been regarded as pure water with no harmful effects on the environment [1]. In many areas, rainwater is still considered as a safe and suitable source of potable water. Developments in science and technology are improving our standard of living, simultaneously causing some pollution into our environment. Rainwater is being polluted by various ways including emissions and effluent outflow from factories, refineries, waste treatment plant, oil or gases of varying quality and quantity directly into the atmosphere. Only the fight against the risks of flooding was taken into account, in which the field of rainwater only covered a purely quantitative view. Over the past decade, it has been clear that urban discharges in rainy weather are the number one problem in water pollution $[2,3]$. Indeed, rainwater from leaching and runoff mobilizes the pollution accumulated in dry weather $[\mathbf{4 , 5}$ ]. In addition, rainwater is likely to disrupt the balance of receiving environments and causes health problems such as contamination of surface and groundwater $[6,7]$. Some remediation is carried out by soils, rivers and other water systems, but the capacity of this self-purification is largely exceeded [8].

Rainwater chemistry has been the subject of intense research for the last two decades because of increased awareness towards environmental problems caused by acid rain. Due to rapid economic development and consequent increase in energy consumption, concerns about air pollution have emerged to be important social and scientific issues in developing countries. Rainwater composition plays vital role in scavenging soluble components from the atmosphere and helps us to understand the relative contribution of different sources of atmospheric pollutants. The chemical composition of rainwater varies from site to site and region to region due to influence of local sources. If the source is influenced by anthropogenic activities, the nature of rainwater becomes acidic because anthropogenic activities contribute acidic gases like sulphur oxide $\left(\mathrm{SO}_{\mathrm{x}}\right)$ and nitrogen oxide $\left(\mathrm{NO}_{\mathrm{x}}\right)$ and a basic gas like $\mathrm{NH}_{3}$. The sulphur and nitrogen compounds that contribute to acid primarily come from manmade sources, such as industries, utilities, automobiles and other form of transportation. When these acidic gases are dissolved in clouds, sulfuric and nitric acids are formed, respectively. In countries like Bangladesh, dust particles are an important part of the atmosphere, which contains significant base cations, these base cations neutralize the acidity of rainwater before being deposited on the ground surface. Therefore, both anionic and cationic indexes are necessary to evaluate the qualitative characteristics of ions in rainwater. Acid rain has recently become a serious environmental problem in many industrialized countries including Japan, all over Europe and northeast areas of the United States and Canada. Atmospheric deposition provides a large component of the nutrient, especially nitrogen, and trace metal input $(\mathrm{Pb}, \mathrm{Cd}$, $\mathrm{Mn}, \mathrm{Cr}$, As) from both natural and anthropogenic sources. 


\section{Materials and methods}

\subsection{Materials}

All reagents were analytical grade (AR) and purchased from Merck, Germany. A calibrated electrical balance (GR-200, A\&D Company Limited, Tokyo, Japan) with high precession was used for weighing purpose. Calibrated glass wares including pipette and volumetric flask were used for sample preparations. They were soaked in $10 \%(\mathrm{v} / \mathrm{v}) \mathrm{HNO}_{3}$ overnight and rinsed with deionized water and dried prior using.

\subsection{The study area description}

Bangladesh, a country in South Asia, is located between $20^{\circ} 43^{\prime}$ to $26^{\circ} 36^{\prime} \mathrm{N}$ with longitude $88^{\circ} 3^{\prime}$ to $92^{\circ} 42^{\prime} \mathrm{E}$ and occupies a territory in the northwestern part of the Indian sub-continent above the Bay of Bengal. It has an area of 147540 square kilometers and a population of 150 million with 75 to 80 percent living in the rural areas. The study area is located at the Rajshahi City Corporation area. Rajshahi city is situated on the river of Padma and is approximately $270 \mathrm{kms}$ away from Dhaka, the capital of Bangladesh. The active highway of Rajshahi with Dhaka and others of the country flows by the side of the study area. The study area is approximately 1.5 square kilometers. Around this area, the samples of rainwater were collected for analysis. The map of the study area indicating the sampling sites were shown in the Fig.1.

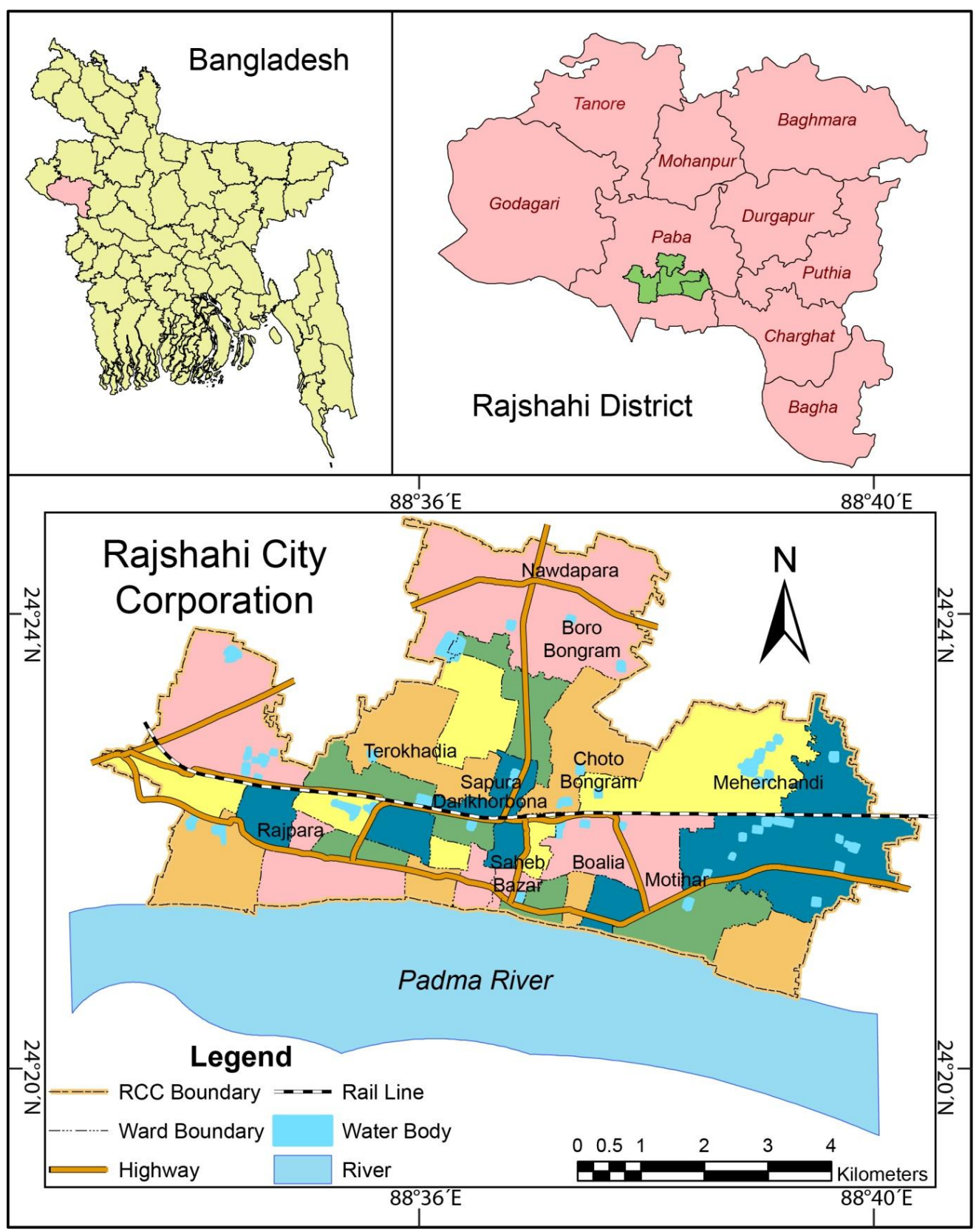

Figure 1: Location of the research area 


\subsection{Collection and preparation of rain water sample}

The sample collection points have been showed in the Fig.1. The samples (rainwater) have been collected of the twenty (20) different places at Rajshahi City Corporation, Rajshahi. Rainwater samples have been collected in clean plastic containers by placing the containers on a raised platform in an open environment of building roofs. The first rainfall was collected from different locations. The collected samples have been divided into two parts for the determination of physicochemical properties and heavy metal analysis.

For physicochemical analysis, samples were collected in 1 liter plastic container taking carefully that no air bubble remains inside. For metal analysis samples were preserved in $500 \mathrm{~mL}$ plastic bottles. The preservation techniques are as follows for various parameters.

\subsection{Sample preparation and analysis}

An investigation is conducted on the status of toxic heavy elements in some rain water samples by using Atomic Absorption Spectrophotometric (AAS) technique. A total of 20 samples including 20 different locations sample were collected from around Rajshahi City area of Rajshahi City Corporation. The rain water samples were brought to the laboratory immediately and physical treatment and chemical analysis were carried out within shortest possible time using standard procedures. $100 \mathrm{~mL}$ of each water sample was taken in a $250 \mathrm{~mL}$ cleaned glass beaker by using a calibrated pipette and acidified with about $45 \mathrm{~mL}$ of concentrated $\mathrm{HNO}_{3}$. The beakers containing the samples were then heated on a hot plate at about $150-180^{\circ} \mathrm{C}$ for digestion and volume reduction to about $25-30 \mathrm{~mL}$. After proper digestion, the cooled sample was taken in a $100 \mathrm{~mL}$ cleaned and calibrated volumetric flask rinsing the beaker several times with deionized water and finally, the flask was made up to the mark. Then it was filtered with a Whatman 42 filter paper and preserved in a previously cleaned and dried $250 \mathrm{~mL}$ nontransparent plastic bottle with a label for the determination of heavy metals concentration. A sample blank was also prepared following the same procedure. The analyzed physicochemical parameters includes: color, odor, transparency, temperature, electrical conductivity (EC), turbidity, total dissolve solid (TDS), total hardness, anions: chloride $(\mathrm{Cl})$, nitrate $\left(\mathrm{NO}_{3}\right)$, sulphate $\left(\mathrm{SO}_{4}{ }^{2}\right)$, and heavy metals viz. lead $(\mathrm{Pb})$, cadmium $(\mathrm{Cd})$, manganese $(\mathrm{Mn})$, chromium (Cr) and arsenic (As). Almost all the parameters were analyzed using standard methods described by APHA [9].

\subsection{Quality Control and data analysis}

During analysis, accuracy and precision were verified by using reference materials from Fluka Analytical, Sigma Aldrich. For analytical quality control, standard solution after each five samples and a reagent method blank after each ten samples were determined. A calibration curve was prepared for all metals by running different concentrations of working standard solutions prepared from CRM. The concentrations of heavy metals of the samples were determined against the prepared calibration curve. Average values of three consecutive replicates were taken for each determination. All stock standard solutions of physicochemical parameters, anions and heavy metals were $1000 \pm 4 \mathrm{mgL}^{-1}$ as traceable to National Institute of Standards and Technology (NIST) and measured against CRM produced and certified in accordance with ISO/IEC 17025 and ISO guide 34. For all locations, three consecutive samples were collected, analyzed and finally their average values were taken.

\subsection{Analysis of physicochemical parameters in rain water}

Water color was observed by naked eyes and odor was felt with nose. Transparency was detected through eye guide of rainwater samples. The water temperature was recorded using a calibrated thermometer at the collection spots. $\mathrm{pH}$, EC and turbidity of all rain water samples, were also measured at the collection spots and for their analysis, a portable multi parameter meter (Model N/F BS 1740, Model HANNA HI 9033 and HI 93703, HANNA) was used which was calibrated using traceable standards and measured instantly. A $100 \mathrm{~mL}$ of water sample was taken in a beaker and the electrode of the meter was immersed into the sample. By changing the machine command, the $\mathrm{pH}, \mathrm{EC}$ and turbidity were measured one by one and the process was followed for each rain water sample. TDS were measured manually as the rain water may contain some organic matter which does not completely ionized in rain water to be detectable by the following relationship [10] TDS (mg/L) $=\mathrm{EC}(\mu \mathrm{s} / \mathrm{cm} \times 0.7)$. The total hardness $(\mathrm{TH})$ was titrated with 0.01 M EDTA [11].

\subsection{Analysis of Anions in rain water}

\subsubsection{Sample Preparation}

At first, the samples were filtered with Whatman TM qualitative 1 filter paper in order to remove sediment and other particulate matter and collected in $25 \mathrm{~mL}$ volumetric flask. Then the filtered samples were taken in sample vials by using syringe with 40 micron filter. Every times, the volumetric flasks, syringes and sample vials were washed with deionized water and rinsed at least three times with the respective samples.

\subsubsection{Instrumental Analysis}

The prepared samples were analyzed by UV Visible spectrophotometer (T60, England) for anions viz. $\mathrm{NO}^{3}$ and $\mathrm{SO} 4{ }^{2}$. $50 \mathrm{~mL}$ sample, filtered by Whatman 42 filter paper was taken in a $50 \mathrm{~mL}$ volumetric flask and $1 \mathrm{~mL} \mathrm{HCl}$ was added. Absorbance was taken in the same manner as for the sample [12]. Instrument baseline was constructed using deionized water. A calibration curve was prepared by running different concentrations of working standard solutions prepared from CRM and concentration of unknown samples were determined against the prepared calibration curve. The sample solutions were transferred into cleaned quartz cell and placed in the path of light source of UV Visible Spectrophotometer to start analysis which gives the concentrations of the sample as nitrate and sulphate determined against the calibration curve. Chloride ion was titrated with $0.02 \mathrm{~N} \mathrm{AgNO}_{3}$ [11]. 


\subsection{Analysis of heavy metals in rain water samples by Atomic Absorption Spectrometer (AAS)}

\subsubsection{Sample Preparation}

$100 \mathrm{~mL}$ of sampled water (acidified with $2 \mathrm{~mL}$ conc. $\mathrm{HNO}_{3}$ per liter) was taken in a $200 \mathrm{~mL}$ flask, heated avoiding boiling to about $8 \mathrm{~mL}$. It was then allowed to cool and put together with flask washing liquid and was increased to 10 $\mathrm{mL}$ with water [12]. 1/10 concentrated liquid was prepared and used for estimation of metallic constituents using AAS.

\subsubsection{Instrumental Analysis}

Heavy metals in the prepared water samples were analyzed by AAS. The $\mathrm{Pb}, \mathrm{Cd}, \mathrm{Mn}, \mathrm{Cr}$ and As concentrations of the rain water samples were analyzed using Atomic Absorption Spectrometer (Model No. AA-6800 Japan). The instrument uses specific hollow cathode lamp (HCL) for each metal under the conditions. A calibration curve was prepared for all metals by running different concentrations of working standard solutions prepared from CRM and concentrations of heavy metals of the samples were determined against the prepared calibration curve. Average values of three consecutive replicates were taken for each determination. All stock standard solutions of physicochemical parameters, anions and heavy metals were $1000 \pm 4 \mathrm{mgL}^{1}$ as traceable to National Institute of Standards and Technology (NIST) and measured against CRM produced and certified in accordance with ISO/IEC 17025 and ISO guide 34.

\section{Results and Discussion}

\subsection{Physicochemical parameters}

The physicochemical parameters of rain water in RCC, were measured as shown Table-1. During the study period in RCC site color of rain water samples were almost natural and all samples were no bad smell in rain water. All samples are of collected rainwater transparent and clear.

\section{Temperature}

Temperature of water plays a vital role to assess the environment of water. The temperatures of all rainwater samples examined remain in the ranges $28.8-29.1^{\circ} \mathrm{C}$ as shown in Table-1. Normally rainwater temperature depends on the atmosphere when rain falls. Hot water contains less oxygen as cold water [13] which is harmful for aquatic life. An effective change in water temperature is dangerous for aquatic fish [14] and other phytoplankton. Achadu et al. (2013) measured temperature in rainwater in Wukari, NorthEastern Nigeria and found the range of $26.5-27^{\circ} \mathrm{C}$ for metal tanks, plastic tanks recorded an average of $27^{\circ} \mathrm{C}$ in all samples and the concrete tanks ranged from $2325^{\circ} \mathrm{C}$. [15].

\section{Electrical conductivity (EC)}

Electrical conductivity indicates the presence of overall ionic species in the water body. EC of rainwater in the Rajshahi City Corporation area of rainy season are varied from 8 to $20.33 \mu \mathrm{Scm}^{1}$ and listed in Table-1. This indicates low mineralization of rainwater. Generally, rainwater is virtually a sample of distilled water and conductivity is remains around $0.05 \mu \mathrm{Scm}^{1}$ Husam et al. (2014) found the $\mathrm{EC}$ of all harvesting rainwater samples ranged from 240 to
1,700 $\mu \mathrm{s} / \mathrm{cm}$. [16]. Alqutob et al. (2012) found the EC of all harvesting rainwater samples ranged from 340-2010 $\mu \mathrm{s} / \mathrm{cm}$ respectively [17].. The WHO standard value of water 1000 $\mu \mathrm{Scm}^{-1}$ [18]. All sites our results showed lower EC values than the standard of according to WHO due to seasonal variations.

\section{Turbidity}

Results on rainwater turbidity are shown in Table-1. It is observed from the table that the values are ranged from 2.33 to $4.88 \mathrm{NTU}$. These values are acceptable and within the permissible limit. Achadu et al (2013) found the Turbidity (NTU) ranged from 1.0-1.5, 1.0-1.2 and 1.0-1.5 in metal, plastic (PVC) and concrete tanks respectively [15]. Highest desirable turbidity limit for drinking water is under 5 NTU and maximum permissible limit is 25 NTU according to WHO [18].. Our results showed that low values of turbidity within determined in all rainwater sampled. This conforms to the acceptable standards and guidelines for potable water quality of 5.0 NTU of WHO.

\section{Total dissolved solids (TDS)}

Rainwater TDS values are measured during the rainy season and arranged in Table 1. It is observed from the table that values range from 7.21 to $14.29 \mathrm{ppm}$. Water samples containing TDS values less than $1000 \mathrm{ppm}$ could be rated as fresh water. Husam et al. (2014) found the TDS of all harvesting rainwater samples ranged from136.7-1,139 $\mathrm{mg} / \mathrm{L}$. [16].The maximum permissible limit of TDS for drinking water is $1500 \mathrm{ppm}$. [19]. According to the standard, our results showed all rainwater samples considered in the present investigation are within the safe limit of TDS value.

\section{pH}

$\mathrm{pH}$ of water indicates the nature of water whether it is acidic, basic or neutral. It controls the biological environment of water area. A drastic increase or decrease in $\mathrm{pH}$ level of water body exerts a fatal impact on aquatic life. Rainwater samples collected from 20 sampling locations within the Rajshahi City Corporation area of the rainy season are studied and it is observed that $\mathrm{pH}$ range between 6.03 and 6.95 which indicate that the samples of the area is slightly acidic in nature. Results are tabulated in Table-1. BWPCB [20] and WHO [21].have recommended the standard values of $\mathrm{pH}$ ranging from 6.5 to 9.2 for drinking water. Husam et al. (2014) found the $\mathrm{pH}$ of all harvesting rainwater samples ranged between 7.1 and 8.2 (with a mean temperature of $18.8^{\circ} \mathrm{C}$ ) which is neutral to slightly basic and in the allowed limit (6.5-8.5) according to WHO regulations [16]. Alqutob et al. (2012) found the $\mathrm{pH}$ of all harvesting rainwater samples ranged between 7.2-7.9 (with mean temperature of $19.0^{\circ} \mathrm{C}$ ) which is neutral to slightly basic and in the allowed limit (6.5-8.5) according to WHO regulations [17]. Where our results showed that the rainwater of all locations in Rajshahi City Corporation area is suitable except 6 samples for drinking but not objectionable to irrigation purpose. It is to be noted that the lowest $\mathrm{pH}$ value recorded in the present work (i.e. 6.03) is from Shonadhogir more (sample no.9) a place of the city centre where gold and silver jewellary manufactory are densely populated. Sampling area no.7 is the city centre and also populated with gold and silver manufactory. These manufactories use mineral acids for their preparations. Sample no. 3 records 
$\mathrm{pH}$ value 6.36; this place is within the Rajshahi University Campus and sit four chemical orientated departments viz. Chemistry, Applied Chemistry, Biochemistry and Pharmacy that use mineral acids for their laboratory experiments. Sample no. 17 is collected from supara industrial area.

\section{Total hardness (TH)}

Total Hardness values of rainwater have been measured in the Rajshahi City Corporation area and tabulated the results is also graphically shown in Table-1. It is observed that the values are ranged from 4.8 to $15.2 \mathrm{mg} / \mathrm{L}$ which indicate the composition of soft water. The highest desirable and maximum permissible limit of hardness values are $100 \mathrm{ppm}$ and 500 ppm as $\mathrm{CaCO}_{3}$ respectively [21]. According to the view of Sawyer et al. (1967), the rainwater samples of the studied area are very soft [22]. Dinrifo et al. (2010) found the $\mathrm{TH}$ of all physicochemical properties of rainwater samples ranged from $15.1-21.3 \mathrm{mg} / \mathrm{l}$ respectively [23]. It is concluded, our results showed that, in general the rainwaters of the area are very soft and no scale formation would be caused in boiler units, heating pipes etc. and need not to be softened again if used for industrial purpose.

Table 1: Mean values of physicochemical parameters of rain water sample from RCC, Rajshahi City Corporation

\begin{tabular}{|c|c|c|c|c|c|c|c|c|c|}
\hline \multirow[b]{2}{*}{$\begin{array}{c}\text { Sample } \\
\text { ID }\end{array}$} & \multicolumn{9}{|c|}{ Name of parameters } \\
\hline & Temperature & $\begin{array}{c}\mathrm{EC} \\
\left(\mu \mathrm{Scm}^{-1}\right)\end{array}$ & \begin{tabular}{|c|} 
Turbidity \\
(NTU)
\end{tabular} & $\begin{array}{c}\text { TDS } \\
(\mathrm{ppm})\end{array}$ & $\mathrm{pH}$ & $\begin{array}{c}\mathrm{TH} \\
(\mathrm{ppm})\end{array}$ & \begin{tabular}{|c|}
$\begin{array}{c}\text { Chloride } \\
\text { (ppm) }\end{array}$ \\
\end{tabular} & $\begin{array}{c}\text { Nitrate } \\
(\mathrm{ppm})\end{array}$ & $\begin{array}{c}\text { Sulphate } \\
\text { (ppm) }\end{array}$ \\
\hline Binodpur-1 & 28.80 & 19.90 & 4.40 & 7.21 & 6.45 & 12.80 & 4.86 & 0.80 & 2.60 \\
\hline Kazla-2 & 28.80 & 11.20 & 4.35 & 7.84 & 6.80 & 12.00 & 2.13 & 0.90 & 4.00 \\
\hline $2^{\text {nd }}$ science -3 & 28.80 & 10.30 & 3.04 & 7.21 & 6.36 & 12.00 & 7.81 & 1.90 & 12.20 \\
\hline ss-hall-4 & 28.80 & 12.30 & 4.38 & 8.61 & 6.89 & 8.00 & 3.50 & 0.00 & 0.20 \\
\hline R- hall-5 & 28.80 & 17.10 & 4.03 & 11.97 & 6.47 & 8.00 & 2.84 & 0.00 & 0.00 \\
\hline RUET -6 & 28.80 & 13.33 & 4.22 & 9.31 & 6.95 & 7.20 & 0.71 & 0.05 & 1.20 \\
\hline Shaheb bazar-7 & 28.78 & 16.55 & 4.67 & 11.58 & 6.33 & 15.20 & 7.81 & 2.60 & 13.00 \\
\hline Alu potti-8 & 28.78 & 17.35 & 4.10 & 12.12 & 6.77 & 8.80 & 7.10 & 3.85 & 5.50 \\
\hline Shonadhigir mor-9 & 28.80 & 13.66 & 4.88 & 9.56 & 6.03 & 11.20 & 3.55 & 5.90 & 3.50 \\
\hline Lumipur-10 & 28.80 & 13.30 & 4.75 & 9.31 & 6.65 & 12.00 & 3.55 & 3.20 & 2.60 \\
\hline Court station -11 & 29.00 & 12.12 & 2.33 & 8.45 & 6.78 & 7.20 & 0.00 & 0.35 & 0.50 \\
\hline Kala bagan -12 & 28.80 & 20.33 & 3.15 & 14.29 & 6.90 & 9.60 & 0.56 & 0.10 & 0.00 \\
\hline New market -13 & 28.90 & 17.00 & 3.22 & 11.90 & 6.60 & 4.80 & 4.97 & 5.65 & 3.20 \\
\hline Railway station-14 & 29.10 & 19.85 & 4.05 & 13.99 & 6.76 & 9.60 & 0.71 & 3.45 & 3.80 \\
\hline Bornali-15 & 29.00 & 9.38 & 3.02 & 6.57 & 6.99 & 8.80 & 2.84 & 0.65 & 2.80 \\
\hline Kadir gonj-16 & 29.00 & 8.00 & 2.98 & 5.60 & 6.78 & 7.20 & 0.00 & 0.00 & 0.00 \\
\hline Spupura-17 & 28.80 & 19.05 & 4.88 & 13.33 & 6.30 & 10.40 & 6.39 & 5.20 & 9.00 \\
\hline Gosh para-18 & 29.00 & 12.50 & 3.10 & 6.02 & 6.90 & 7.20 & 0.00 & 0.90 & 0.00 \\
\hline Dargapara-19 & 29.00 & 11.60 & 2.90 & 8.12 & 6.60 & 8.80 & 0.00 & 0.00 & 0.70 \\
\hline Vadra-20 & 29.00 & 18.30 & 4.30 & 12.81 & 6.70 & 8.80 & 0.71 & 2.70 & 1.30 \\
\hline
\end{tabular}

\section{Chloride ion $\left(\mathrm{Cl}^{-}\right)$}

The chloride concentrations of the rainwater samples at twenty sites are shown in Table 1 . It is evident from the results that chloride content of rainwater samples of the study area varied from 0.00 to $7.81 \mathrm{ppm}$. Chloride in four locations of Rajshahi City Corporation is not detectable. Achadu et al. (2013) found the chloride ion in harvested rainwater metal tanks and plastic (PVC) tanks gave the range for $<0.01-0.90 \mathrm{mg} / \mathrm{L}$ and $<0.01-1.20 \mathrm{mg} / \mathrm{L}$ respectively [15]. Benrejdal et al. (2017) found the $\mathrm{Cl}^{-}$of rainwater samples ranged from $2.13-3.55 \mathrm{ppm}$ respectively [1]. Water containing less than $250 \mathrm{ppm}$ chloride, is suitable for drinking, agriculture and industrial purposes [24]. In view of the above fact, the chloride content of the rainwater in this investigation in all cases lies within the level recommended for drinking and household purposes. The lower concentrations of $\mathrm{Cl}^{-}$in the present study indicates that there is no chlorinated pesticide pollution in the RCC of rainwater which may be found due to the addition of pesticides in the surrounding agricultural lands of the RCC.

\section{Nitrate ion $\left(\mathrm{NO}_{3}{ }^{-}\right)$}

The nitrate concentrations of the rainwater samples are shown in Table-1. It is seen from the table that the concentrations of nitrate ion in all the sample of rainwater are ranged from 0.00 to $5.90 \mathrm{ppm}$. In four samples of nitrate concentration is not detectable. Achadu et al. (2013) found the nitrate ion in harvested rainwater metal tanks and plastic (PVC) tanks gave the range for $<0.01-3.1$ and 0.2-2.1 ppm respectively [15]. Benrejdal et al. (2017) found the $\mathrm{NO}_{3}{ }^{-}$of rainwater samples ranged from 5.765 - $10.358 \mathrm{ppm}$ respectively [1]. Amount of nitrate ion at all investigation points throughout the study area is below the highest permissible limit [21] 10 ppm for drinking purpose of man and livestock. In view of the above fact, it is concluded that the rainwater is safe for human consumption in terms of nitrate content.

\section{Sulphate ion $\left(\mathrm{SO}_{4}{ }^{2-}\right)$}

The results of sulphate content in rainwater have been arranged in Table-1. It is observed that sulphate in rainwater of study area is limited between 0.00 to $13 \mathrm{mg} / \mathrm{L}$ throughout the rainy season and locations investigated. Four samples for sulphate is not detectable. Achadu et al. (2013) found the sulphate ion in harvested rainwater metal tanks and plastic (PVC) tanks gave the range for 1.8- 5.8 and 2.01-5.3 mg/L respectively [15]. Benrejdal et al. (2017) found the $\mathrm{SO}_{4}{ }^{2-}$ of rainwater samples ranged from 7.864 - $19.025 \mathrm{ppm}$ respectively [1]. According to the United State Public Health Service (USPH) drinking water standard, the potable water should not contain more than $250 \mathrm{ppm}$ of sulphate ion [25]. The maximum permissible limit $250 \mathrm{ppm}$ recommended by USEPA (1969) and WHO [21] for drinking and household purpose. 


\subsection{Heavy metals concentration in rain water samples}

High concentrations of lead in the body can cause death or permanent damage to the central nervous system, brain, and kidneys. According to the recently released lead toxicological profile for lead from the Agency for Toxic Substances and Disease Registry (ATSDR), the adverse health effects of lead range from slight increases in blood pressure at $100 \mu \mathrm{g} / \mathrm{L}$ to severe retardation and even death at very high blood lead levels of $1,000 \mu \mathrm{g} / \mathrm{L}$ [26]. Concentrations of lead at different investigation points have been shown in Fig.2. It is observed from the figure that the values are ranged from 1.0982 to $11.9124 \mathrm{ppb}$. The concentration of lead from harvested rainwater in Hebron (south west bank, palestine) was in range of 12.94486 .4 [16]. Which are within safe level and below the toxic limit in almost all the places. The maximum permissible limit $0.05 \mathrm{ppm}$ recommended by WHO [21] for drinking water. Our results showed that, all rainwater samples in Rajshahi City Corporation area are acceptable for drinking purpose except sample no. 7 and 17. Sample 7 was collected from the centre city market (called Shaheb Bazaar) which was always burdened with heavy vehicular traffic and sample 17 was from the industrial belt of Rajshahi City Corporation. The results of lead concentration are shown graphically in Fig.2.

The measured cadmium concentrations are arranged in fig.3. It is seen from the table that the concentration of cadmium in all the sample of rainwater are ranged from 0.0651 to 0.4940 ppb. The concentration of cadmium in harvested rainwater from hebron (south west bank, palestine) was in range of 0.02 .19 [16]. The maximum permissible limit $0.005 \mathrm{ppm}$ recommended by WHO [21] for drinking purpose of man and livestock. Hence it can be said that our results showed, the sampled rainwater are free from cadmium concentrations. The results of cadmium concentration are shown graphically in Fig.3. The experimental results of manganese in rainwater samples are tabulated in fig. 4 and graphically shown the Fig. 4 In the present investigation, the collected rainwater samples show $\mathrm{Mn}$ concentration in the range of 0.2035 to $1.750 \mathrm{ppb}$ in the rainy season. The concentration of manganese in harvested rainwater from Hebron (south west bank, palestine) was in range of 4.56552.3 [16]. Usually the concentrations are within the permissible limit $0.05 \mathrm{ppm}$ according to drinking water standard as recommended by WHO [21]. It is obvious that our result showed that the concentration of $\mathrm{Mn}$ in rainwater in the study area is within the recommended value and thus can be considered suitable for drinking purpose in terms of Mn concentrations.

Concentration of chromium in rainwater in the Rajshahi City Corporation area of rainy season are varied from 0.0421 to $1.9740 \mathrm{ppb}$ and listed in fig.5. The concentration of chromium in harvested rainwater from Hebron (south West Bank, Palestine) was in range of 22.6-165.5 [16]. Maximum permissible limit of chromium in drinking water is $0.05 \mathrm{ppm}$ recommended by (WHO [21]. It is evident that our results showed the rainwater over the Rajshahi City Corporation area is free from $\mathrm{Cr}$ contamination and thus suitable for human consumption.

Concentrations of arsenic at different investigation points has been evaluated and arranged in graphically shown in the Fig.6. The concentration of arsenic in harvested rainwater from in Gaza by using ICP/MS was in range of 0.4325 .0 [17]. The concentrations of arsenic of rainwater are ranged from 1.531 to $2.7465 \mathrm{ppb}$. The maximum permissible limit $0.05 \mathrm{ppm}$ of arsenic recommended by WHO [21] for drinking purpose of man and livestock.

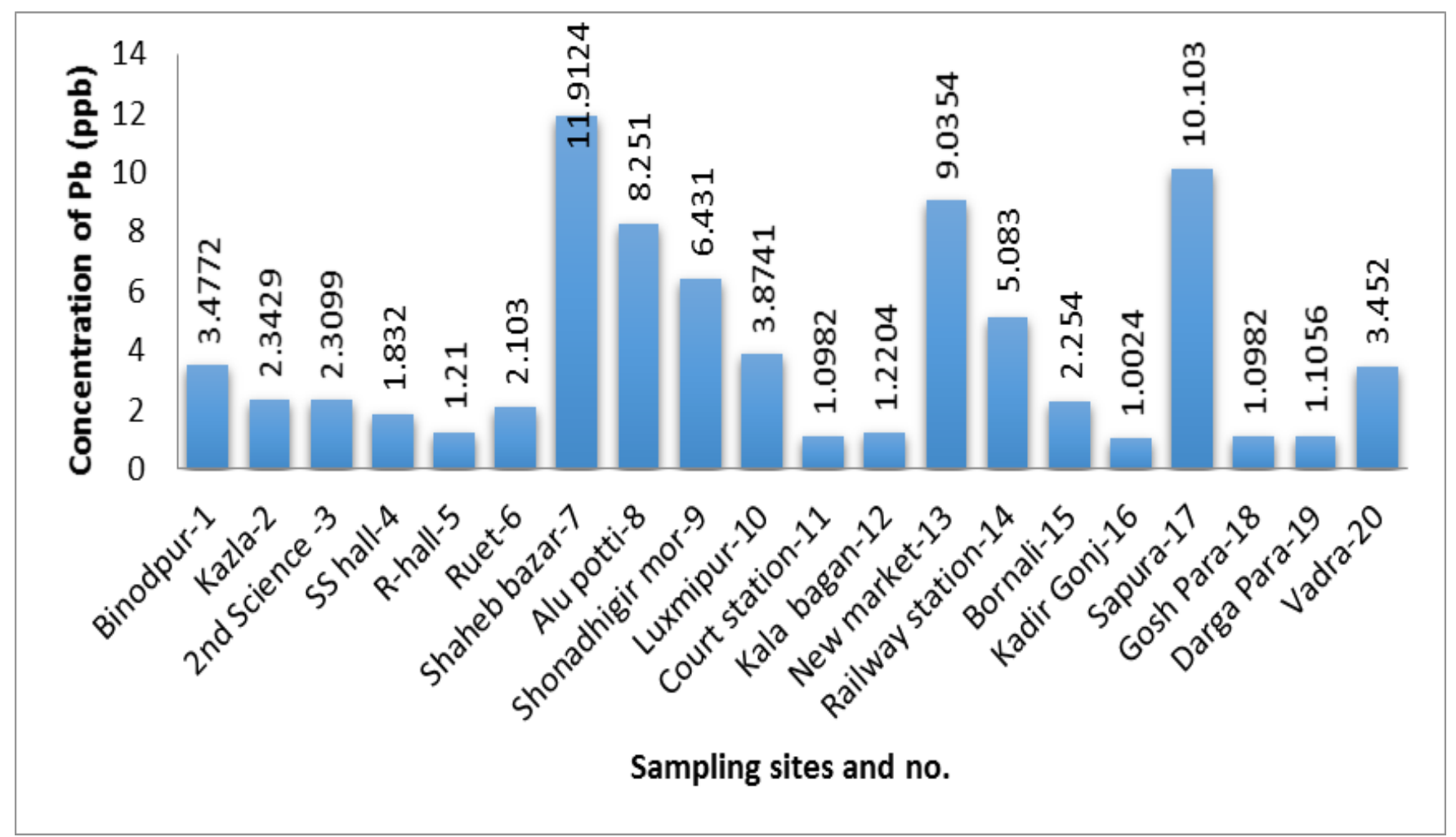

Figure 2: Concentration profile of lead in rainwater at the RCC 


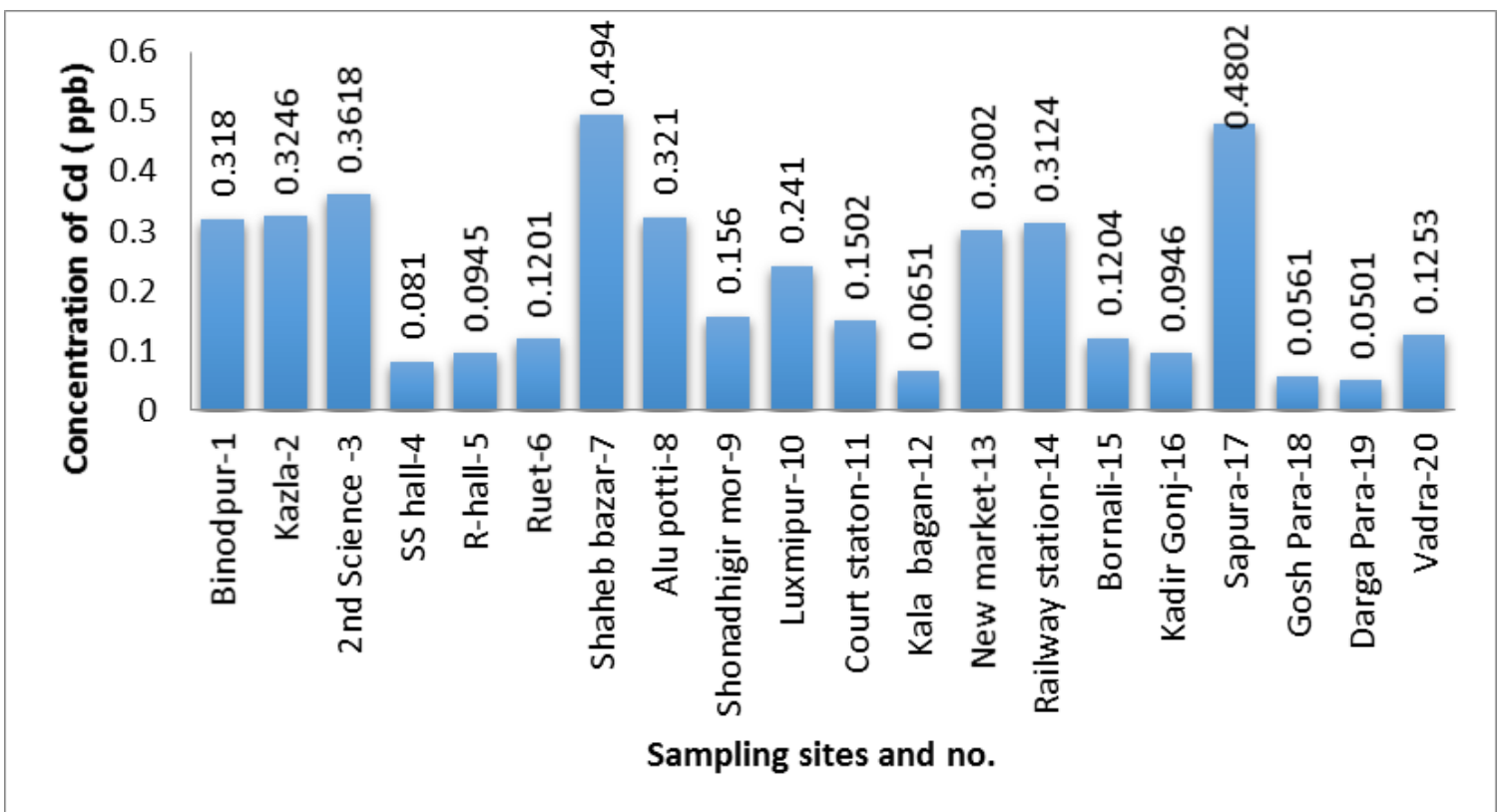

Figure 3: Concentration profile of cadmium in rainwater at the RCC

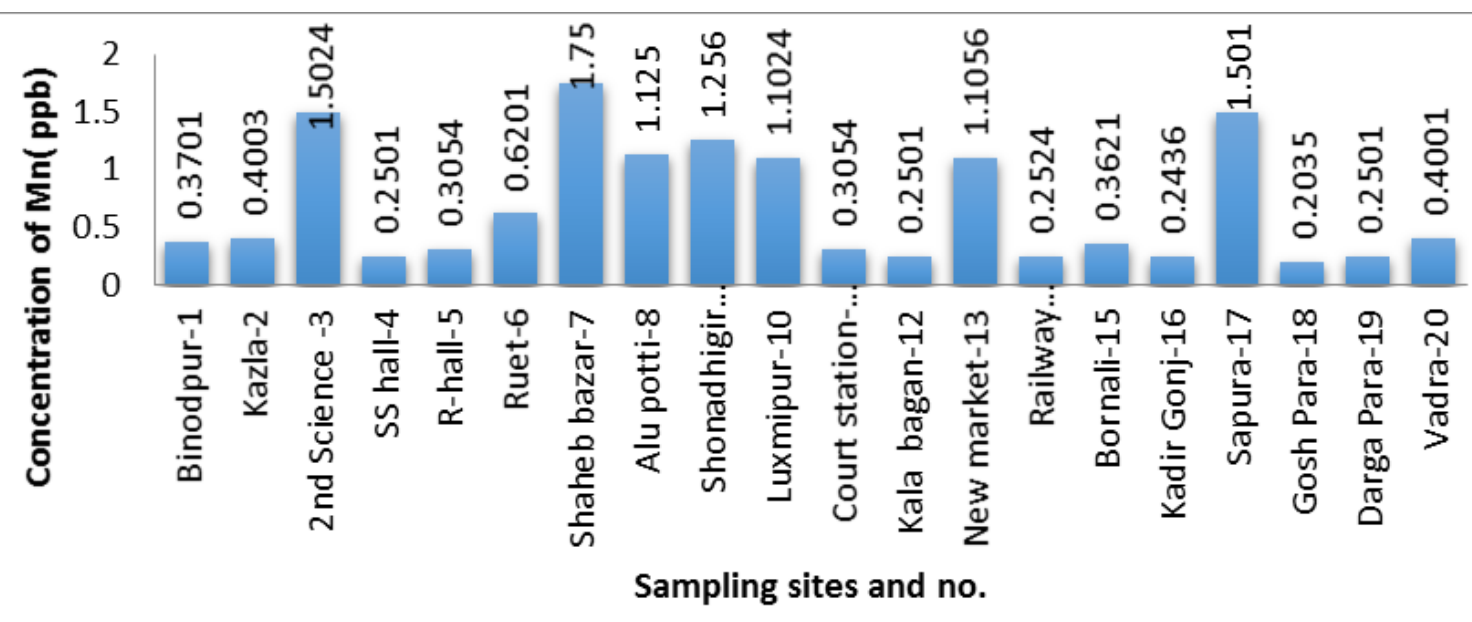

Figure 4: Concentration profile of manganese in rainwater at the RCC

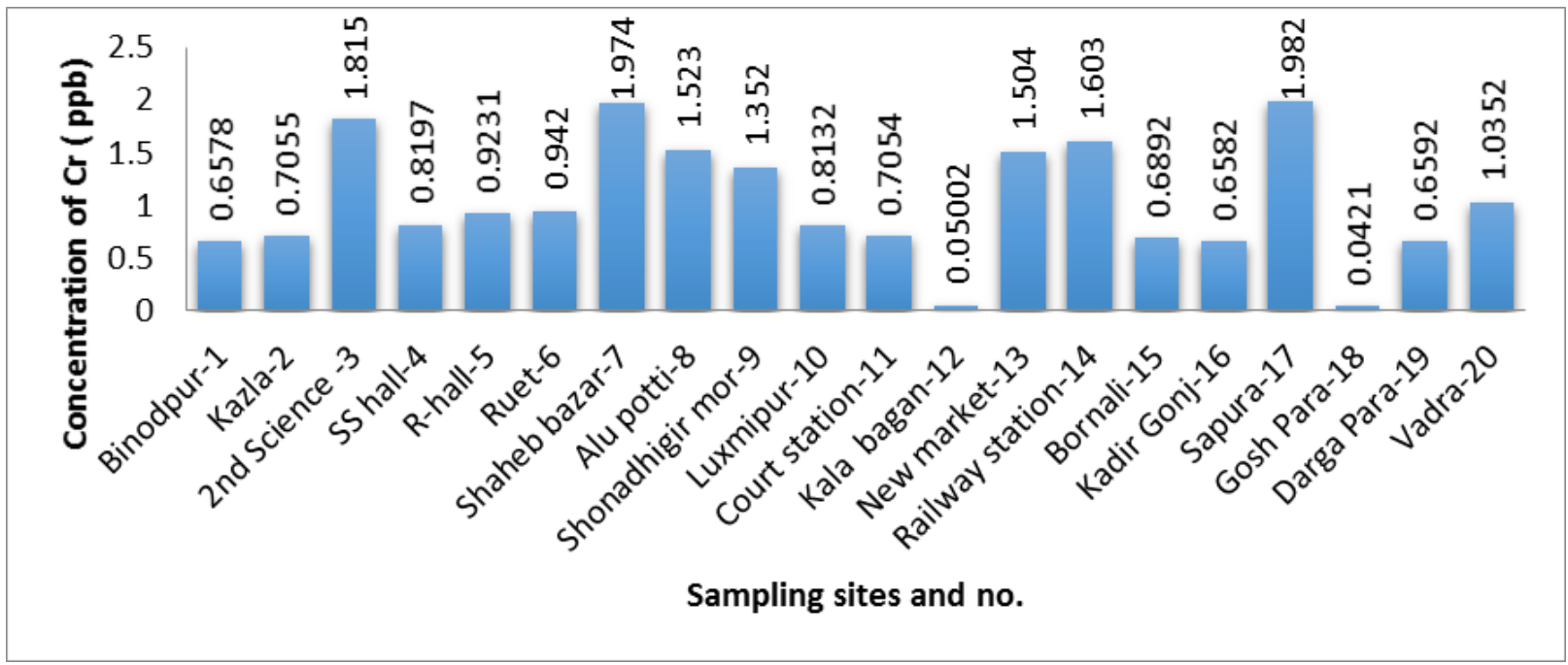

Figure 5: Concentration profile of chromium in rainwater at the RCC 


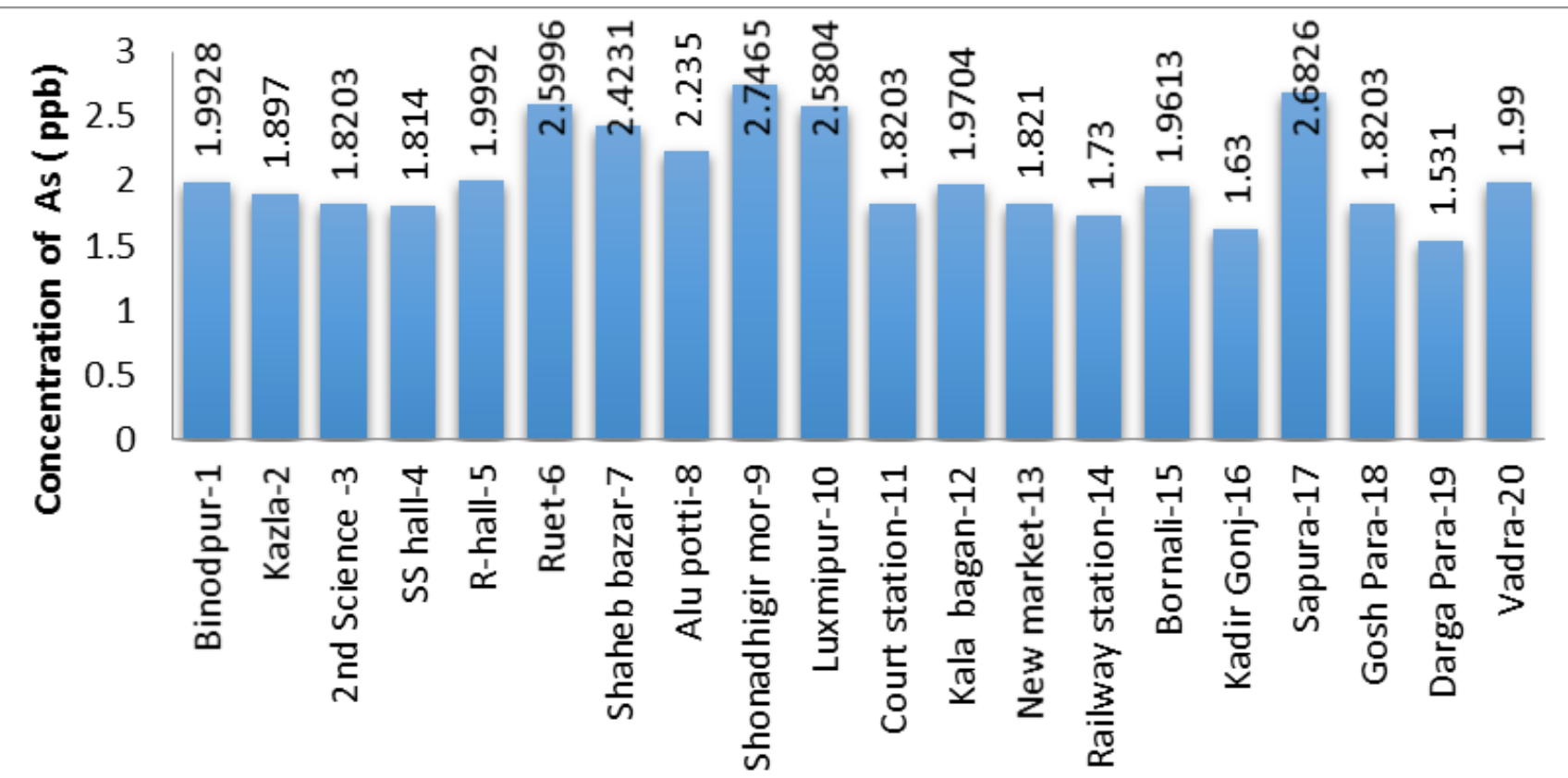

Sampling sites and no.

Figure 6: Concentration profile of arsenic in rainwater at the RCC

\section{Conclusion}

The analysis of rainwater of Rajshahi City Corporation area is very important for it plays an essential role in the whole range of urban environment. Physicochemical characteristics and suitability of the rainwater of this area are studied with special reference to its portability. A total of twenty rainwater samples were collected from different places of the Rajshahi City Corporation. The samples were collected as per standard procedures. After a careful examination, it is observed that the rainwater of the area is colorless, odorless, tasteless and transparent. Results of $\mathrm{pH}$ of the rainwater in the area are acidic. The lowest conductivity values might be due to low concentrations of ionic constituents present in the rainwater. Total hardness was found very soft water respectively. The water is safe for drinking purposes, in terms of chloride and sulphate content. Lead content the rainwater of the Rajshahi City Corporation area is suitable for drinking (except samples 7 and 17, i.e rainwater over city centre and sapura industrial belt). Cadmium, manganese chromium and arsenic contamination are not observed; values of $\mathrm{Cd}, \mathrm{Mn}, \mathrm{Cr}$ and $\mathrm{As}$ concentrations are within the recommended limit. It is concluded that the quality of rainwater in the area is in general good for the utilization in drinking, agriculture, industrial or domestic purposes.

\section{Acknowledgement}

The authors deeply thankful to Central Science Laboratory of Rajshahi University, Rajshahi for providing all necessary research facilities.

\section{References}

[1] Benrejdal, F., Haddad, H., Ghoualem, H. (2017). Physico-chemical characterization of rainwater of the area of Algiers Valorization, Journal of Materials and Environmental Sciences 8, 2347-2352.

[2] Hartemann, P. (2004). EMC-Toxicologie Pathologie, 163-78.

[3] Villemant, C. (1981). Environmental Pollution (Series A). 24, 245-262.

[4] Dubois, C., (1994). Agence de l'Eau Artois Picardie. 61.

[5] Santos, P.S.M., Otero, M., Santos, E.B.H., Duarte, A.C. (2011). Science of the Total Environment. 409 3548-3553.

[6] Pourchet, A., Sibeud, E.E. (2013). Communauté Urbaine de Lyon - Direction de l'Eau.

[7] Gromaire-Mertz, M.C., Chebbo, G., Saad, M. Mouche, J.M. (1997). LA Houille Blanchfj. 7.

[8] Benyahya, M., Bohatier, J., Laveran, H., Senaud, J., Ettayebi, M. (1998). Année Biol 78, 95-105.

[9] APHA (1998). Standard Methods for the Examination of Water and Wastewater, American Water Works Association, Water Environment Federation, USA, 22nd edition.

[10] Metcalf, E., Burton G., Stensel, H.D. (2003). Wastwater Engineering, 4th ed. Tata McGraw Hill Pub. Co. New Delhi.

[11] Tripathi, B.D., Govil, S.R. (2001). Water Pollution (An Experimental Approach). CBS Publication. New Delhi.

[12] Eaton, A.D., Clesceri, L.S., Greenberg, A.E. (1995). Standard Methods for the Examination of water and wastewater Publication Health Association, Washing D.C. 19th cd.

[13] Mandal, H.S., Das, A., Nanda, A.K. (2012). Study of some physicochemical water quality Parameters of Karola River, West Bengal-an attempt to estimate pollution status, Int. J. Environ. Prot. 2, 16-22. 